\title{
ReVIEW I When Genres Collide: Down Beat, Rolling Stone, and the Struggle Between Jazz and Rock
}

Matt Brennan

London and New York: Bloomsbury, 2017

ISBN: 9781501326141 (PB)

\section{Fernando Aparecido Poiana São Paulo State University (UNESP) fernando_poiana@hotmail.com}

It is hard to unequivocally identify the elements that define a musical genre. Nor is it easy to gauge the extent to which a genre's staying power is determined by its immanent musical traits or is influenced by external, non-musical circumstances. Through this publication, Matt Brennan argues that the latter are key factors in this cultural equation. In what reveals itself to be a fully substantiated study, the author argues that the response to jazz and rock ' $n$ ' roll given by specialized critics was essential to circumscribe these genres within artificial limits brimming with aesthetic and ideological disputes, an argument perceptively demonstrated throughout this publication.

Broadly speaking, Brennan's book is a thorough discussion of the editorial policies of Down Beat and Rolling Stone. The author also examines how these publications contributed to establish and strengthen the American music press as an authoritative institution. With that in mind, Brennan analyses the standard editorial practices of these two magazines by commenting on the editors' musical tastes and political inclinations. In addition, he explores how the critics who regularly contributed to Down Beat and Rolling Stone influenced the ways in which jazz and rock were enjoyed and understood by a large audience that included occasional listeners, music enthusiasts, fellow critics, aspiring musicians, and experienced recording artists. Even though he focuses his analysis on these two publications, Brennan considers several important others in passing, strengthening what is an already substantive contribution. In doing so, the author also creates a comprehensive music scene that presents the reader with the ideological atmosphere in which the work of now legendary jazz and rock artists 
were assessed by music critics for the first time and officially put on the cultural map of the period.

One of the main ideas of the book, revisited by the author throughout, is that "the history of music journalism is central to understanding the formation of popular music genres" (18). Implicit in Brennan's words here is the belief that trying to explain the endurance of jazz and rock by solely examining the technical or compositional traits of the songs and records is very likely to return inconclusive verdicts. This question is much more complex - hence the relevance of the author's critical method and approach. Brennan sees these technical aspects as insufficient to safely categorize jazz or rock as genres, given that the criteria to establish these dividing lines extend beyond musical quality or artistic merit. In other words, the idea of genre is conceived as something that transcends the merely musical aspects of a set of compositions. This explains, for instance, his insistence on the comprehensive notion of "genre cultures" (24) that permeates the book and provides theoretical coherence. Here, Brennan refines the concept of genre to also embrace moral, social, historical, and ideological aspects.

Brennan states that, given the power of editors and critics to decide on what to cover and how to do so, "music genres (...) emerge from a collective dialogue" (23) in which music journalism is an influential mediator. Furthermore, he states that "the popular music press has played a crucial role in simultaneously reflecting and shaping these discourses" (185), and that these discourses in turn have been highly influential in the dominant definitions of genre boundaries that act to separate and define jazz and rock. Ultimately, Down Beat and Rolling Stone have been important in connecting musicians and bands and their target audiences, the history of such actions aptly demonstrated within this publication. The author implies that jazz and rock have been defined and redefined through the piles of critical reviews and full-length articles published in such magazines. For him, the ways critics responded to (and drew the dividing lines between) jazz and rock as new records were released and new artists entered the scene helped both genres to achieve their status in popular culture.

Brennan also claims that "music critics and journalists are a key constituency in both jazz and rock scholarship and institutions beyond the academy" (190), investigating the aesthetic and commercial criteria behind the creation and dissemination of authoritative discourses about popular music. In scholarly terms, he implies, this reverberates in the kinds of academic research conducted in the field of music studies today, especially those that take a historiographical approach. In commercial terms, however, the author argues that the establishment of a genre "is arguably the key structuring device for how popular music is made and heard, taught and learned, bought and sold, and supported or suppressed" (23); the music industry quickly realized that you must name and pigeonhole something before selling it. Without these notions of genre and their powerful influence on the consumption of music, the music industry as we know it might never have survived, or indeed even existed.

Considering the ample scope of Brennan's analysis, as well as the broad range and power of his arguments, this book indeed reads both as "a history of the formative years of American jazz and rock journalism on the one hand, and a history of the relationship between jazz and rock ' $\mathrm{n}$ ' roll, and rock in the years leading up to fusion on the other" (184). Brennan demonstrates that the ideological rifts which drove a critical wedge between jazz and rock ' $\mathrm{n}$ ' roll, and led to the disputes alluded to in the title of the book, occurred when still-incipient music coverage wrestled with the idiosyncrasies of both genres, trying to make 
sense of their musical aesthetics on the one hand, while also thinking of ways to target audiences which might potentially consume that music.

The bottom line of Brennan's argument, then, is that "jazz and rock are different genres, but this difference is historically constructed" (184). As such, the criteria adopted to distinguish aesthetic nuances of each genre are charged with the mores and prejudices of the period when these parameters were set. And it is here that the revisionist ethos of Brennan's book becomes more prominent. Even though jazz and rock artists and bands may sound differently (and they often do), what Brennan suggests is that their musicality is rarely taken into account when it comes to drawing a musical line between them. As the author claims, "rock could have been part of jazz, but did not become so for particular reasons, and it is possible to reconsider key periods in music history when the boundary between the two was not nearly so clear" (184). He also adds that his "investigation aligns with the recent work of David Brackett [2016] on the practice of music categorization and the emergence of music genres" (184).

As Brennan explains "jazz and rock worlds have continued to intersect and collide since the time frame of my research" (192): this separation is therefore posited to be an artificial one created, fostered, and consolidated by music journalists or critics. The author suggests that there is a gap, then, between jazz and rock as genres which tend to musically attract each other on the one hand, and the type of music criticism that insists on keeping them as far apart as possible on the other. The result of this process is a constant musical and critical tension. As Brennan argues "the definitions of jazz, rock, and popular music continue to be negotiated, as they have been throughout their existences" (193). When read in the context of the book, this statement exposes the conflict of interests behind the criteria employed by critics to categorize (or even forge) music genres.

The themes and arguments of this publication are thought-provoking, inviting the reader to take another look at the notions of music genre he or she might have already taken for granted. One of Brennan's most important contributions to the field of music studies, then, is a scrutiny of the meanders of music criticism in his examination of some of the ideological premises which shape this critical discourse. By doing so, he reminds us that unbiased criticism is just fallacious. This, when read in tandem with the social analyses Brennan engages in throughout the book, reveals that this publication also has a subtle political edge that makes it an especially gripping read.

\section{References}

Brackett, D. 2016. Categorizing Sound: Genre and Twentieth-Century Popular Music. Berkeley, CA: University of California Press. 